\title{
LA ARQUITECTURA DEL BAÑO DE VAPOR EN LA CULTURA MAYA
}

\author{
Nuria Matarkedona Desantes \\ Universitat Politècnica de València
}

Resumen: El baño de vapor, pese a haber sido poco estudiado, es uno de los elementos constructivos más singulares de la civilización maya. El artículo aborda su análisis arquitectónico como herramienta imprescindible para la necesaria conservación y puesta en valor de esta arraigada tradición desde tiempos prehispánicos hasta nuestros días.

Puesto que se considera fundamental la aproximación a su arquitectura desde el análisis etnográfico y etnohistórico de su contexto mesoamericano, donde se le conoce como "temascal", a partir de un exhaustivo proceso de documentación, el trabajo analiza comparativamente los edificios identificados como temascales y contribuye a estructurar un mayor conocimiento científico sobre los conceptos fundamentales de este elemento arquitectónico.

Palabras Clave: maya, arquitectura, temascal, baño de vapor, conservación.

AвSTRACT: Steambaths are one of the most singular and yet barely studied building types from the Maya civilization. The present study addresses its architectural analysis as an essential tool for the preservation of this deeply rooted tradition from Prehispanic times till today.

It is considered fundamental to approach this issue from an ethnographic and ethnohistoric view of its Mesoamerican context, where these baths are known as temascal.

Based on a thorough documentation process, this paper analyzes comparatively those buildings identified as temascal. It contributes to structure a deeper scientific knowledge on the fundamental concepts of this architecture.

KEYworDs: Maya, architecture, temascal, steambath, conservation.

RECEPCIÓn: 23 de enero de 2014.

ACEPTACIÓN: 21 de mayo de 2014. 



\title{
LA ARQUITECTURA DEL BAÑO DE VAPOR EN LA CULTURA MAYA
}

\author{
Nuria Matarredona Desantes \\ Universitat Politècnica de València
}

\section{Introducción}

Desde la antiguiedad, el baño ha gozado de cierta relevancia cultural puesto que, más allá de la mera finalidad higiénica, es habitual que se le atribuyan funciones terapéuticas, sociales e incluso ceremoniales. En efecto, la limpieza del espíritu se ha vinculado tradicionalmente a los rituales de higiene física. La repercusión de esta práctica en las distintas civilizaciones ha quedado patente en la imponente arquitectura asociada a la misma.

La costumbre del baño de sudoración, consistente en la eliminación de toxinas por transpiración, se extiende en territorios dispares del Viejo y el Nuevo Mundo. Su práctica no es homogénea, siendo la principal diferencia el modo de elevar la temperatura de la estancia para crear un ambiente considerablemente cálido que induzca la sudoración. En Mesoamérica, se logra generando grandes cantidades de vapor mediante el vertido de agua sobre piedras calientes hasta lograr su ebullición. En esta región, su uso se considera un rasgo cultural definitorio y adquiere el nombre genérico de temascal (Kirchhoff, 1983) (figura 1).

El presente trabajo profundiza en el estudio arquitectónico de esta tipología edilicia, una de las más singulares y todavía poco estudiadas en el contexto de las antiguas ciudades mayas, de modo que no sólo se facilite su correcta identificación sino que puedan definirse estrategias de conservación y revaloración más adecuadas. ${ }^{1}$

Tales edificios, que sabemos se utilizaban como baños de vapor de forma similar a la que en la actualidad sigue usando la población indígena, responden a una triple función: higiénica, terapéutica y ceremonial. Esto los convierte en nexos entre lo

\footnotetext{
${ }^{1}$ Agradezco el apoyo del Ministerio de Ciencia e Innovación que financió el proyecto de investigación BIA2007-66089, cofinanciado con los fondos FEDER, así como el patrocinio del Ministerio de Cultura a través de la financiación obtenida por el Proyecto Arqueológico La Blanca. Reconozco igualmente el apoyo del programa de Estancias Breves para investigadores en formación, del Gobierno de España, que me ha permitido continuar esta investigación en distintas instituciones, como el Penn Museum of Archaeology and Ethnography de la University of Pennsylvania, el Peabody Museum of Archaeology and Ethnology de Harvard University, Carnegie Institution, el Instituto de Antropología e Historia de Guatemala y el Centro de Estudios Mayas del IIFL de la UNAM. A estas instituciones y, en especial, a su personal, mi más sincero agradecimiento por su colaboración. Agradezco también al Instituto de Restauración del Patrimonio Arquitectónico de la Universitat Politècnica de València y al Dr. Gaspar Muñoz Cosme por su respaldo para el desarrollo de esta investigación.
} 
terrenal y lo sobrenatural; lugares donde se rinde culto tanto al cuerpo como a las deidades. El estudio de los mismos implica profundizar en la cosmovisión maya, un adentramiento en esta civilización milenaria que reflejaba sus planteamientos sociales y políticos en el diseño de sus edificios.

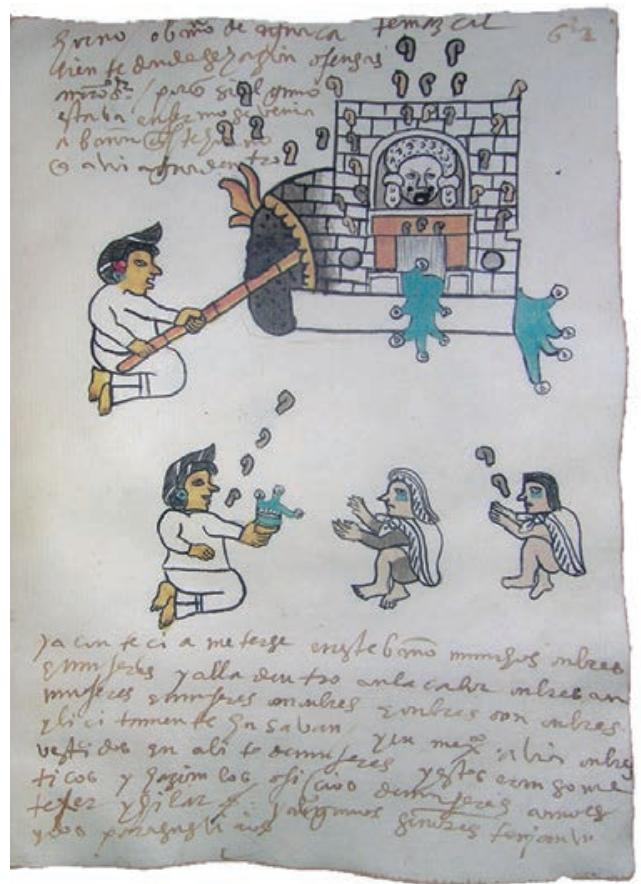

Figura 1. Códice Tudela, lámina 62 (frente).

Las características formales, funcionales y constructivas de dichos edificios son el reflejo de su significado e importancia dentro de las ciudades mayas. En este sentido, el análisis de la arquitectura de los baños de vapor debe aproximarse desde distintas disciplinas, mediante una sinergia de miradas complementarias, esencial para una comprensión global de estas complejas construcciones.

Paradójicamente, la figura del temascal, cuya relevancia ha despertado en las últimas décadas el interés de ciencias como la medicina o la antropología, no ha sido hasta ahora objeto de un estudio arquitectónico propiamente dicho. En esta línea apenas pueden destacarse aportaciones puntuales - como la de Tyrakowsky (2007), que analiza el desarrollo arquitectónico de los baños de vapor en asentamientos rurales de la región de Puebla-Tlaxcala - que contrastan con las numerosas publicaciones respecto a los beneficios terapéuticos o a la repercusión social de una tradición que sigue viva entre indígenas y nuevos adeptos.

La mayor parte de las referencias a la arquitectura del temascal prehispánico provienen de la arqueología. Los primeros artículos publicados por Arreola (1920) 
y Cresson (1938) han sido referencia obligada en toda discusión posterior sobre los baños de vapor. Más tarde, Satterthwaite (1952) realizó la aportación más importante al conocimiento de esta tipología al sistematizar la información referente a los ocho supuestos temascales hallados en Piedras Negras y presentar un análisis comparativo. Los estudios en este sitio arqueológico, único por el elevado número de baños identificados, se complementan con los trabajos desarrollados en fechas más recientes por Child y Child $(2000,2001)$.

Por su parte, la contribución de Alcina et al. (1980) significó el primer acercamiento al concepto de temascal rural en contraposición al urbano a raíz de los hallazgos en el sitio de Agua Tibia, Guatemala. En esta línea conviene destacar la aportación de McKee (1997) sobre el posible temascal de adobe localizado en Joya de Cerén, una aldea abandonada en forma precipitada por sus habitantes al entrar en erupción el volcán Loma Caldera, lo cual provocó que quedara enterrada bajo las cenizas, hasta ser descubierta en 1976. Por ello, presenta unas condiciones muy particulares de conservación.

No obstante, considerando la evolución del conocimiento sobre esta civilización, resulta necesaria una actualización sobre el temascal y su arquitectura.

Hasta el momento, los registros ${ }^{2}$ de temascales prehispánicos identificados en el área maya se han retroalimentado de una serie de referencias bibliográficas, incluso meras comunicaciones personales, que no han vuelto a ser revisadas. En estos elencos queda patente la carencia de descripciones alusivas a los rasgos identificativos que conllevaron dicha determinación y, por tanto, resulta complicado contrastar la idoneidad de estas clasificaciones así como establecer un análisis comparativo de los atributos que denotarían su carácter.

Esta investigación analiza las características arquitectónicas del temascal maya de la antiguiedad, es decir, aquellos elementos esenciales que le permiten a tal edificio ser adecuado para satisfacer sus funciones. Para ello, en primer lugar, se realiza un análisis exhaustivo de las fuentes disponibles, publicadas o inéditas, para obtener documentación referente a aquellas construcciones reconocidas hasta el momento en la bibliografía específica ${ }^{3}$ como baños de vapor. Después, esta información se sistematiza mediante fichas elaboradas ex profeso y, finalmente, es objeto de análisis, de modo que se defina una clasificación contrastada de aquellos rasgos que puedan considerarse característicos de esta tipología.

Esta pequeña contribución al conocimiento arquitectónico de los baños de vapor supone un mejor entendimiento de estas construcciones y, por ende, un avance para su oportuna conservación y valoración.

\footnotetext{
${ }^{2}$ Las clasificaciones más exhaustivas son las realizadas por Ichon, 1997; Alcina et al., 1980; Groark, 1997 y, recientemente, Child, 2007.

${ }^{3}$ En el transcurso de la investigación se ha tenido conocimiento de otras construcciones identificadas como temascales que no habían aparecido en ningún listado hasta el momento. El futuro análisis de los mismos resultaría altamente enriquecedor para configurar un catálogo completo de esta tipología.
} 


\section{Método}

La estrategia de investigación persigue un mejor entendimiento de las características arquitectónicas del temascal maya prehispánico. El método consta de cuatro fases.

En primer lugar se procede a identificar los casos de estudio partiendo de los registros de edificios prehispánicos clasificados como baños de vapor en la bibliografía específica. La segunda fase es la relativa a la documentación bibliográfica, que implica el vaciado en los fondos de bibliotecas especializadas y se complementa con una serie de visitas a las principales instituciones implicadas en la excavación de estas construcciones con el fin de revisar los informes arqueológicos. En una tercera fase, ya en gabinete, la información se sintetiza y sistematiza mediante fichas elaboradas al efecto y es procesada de modo que pueda establecerse, en la cuarta fase, un ulterior análisis comparativo entre aquellos casos para los que se tiene información suficiente y representativa. El estudio de los resultados obtenidos constituye las conclusiones de este trabajo.

\section{Consideraciones previas}

Como punto de partida, resulta imprescindible conocer el funcionamiento higiénico, terapéutico y ceremonial de este tipo de construcciones. Y ésta es, precisamente, una de las primeras limitaciones a las que se enfrenta el estudio: la falta de fuentes de documentación más allá de las propias evidencias arqueológicas. Este hecho implica recurrir necesariamente a otras complementarias que puedan aportar información en cuanto al uso de dichas edificaciones.

Gracias a los numerosos estudios de carácter antropológico, etnográfico, sociológico e incluso medicinal relacionados con el empleo del temascal podemos comprender el conocimiento funcional y simbólico de esta práctica. Dichos estudios ponen de manifiesto que tal práctica milenaria ha sobrevivido gracias a su arraigo en el pueblo indígena que ha mantenido fundamentalmente sus funciones higiénicas y terapéuticas (Cresson, 1938: 90). Este dato permitiría que, a partir de los estudios antropológicos y etnográficos del temascal actual, podamos inferir, en cierta manera, el modo de funcionamiento y los principales objetivos perseguidos mediante el baño de vapor en la antigüedad, a pesar de ser evidente la diferencia existente entre la mayor parte de los temascales mayas arqueológicos identificados y aquellos contemporáneos.

Ante esta cuestión, debemos recordar que el estudio del temascal desde una perspectiva histórica refleja que el empleo del mismo era habitual en todas las capas sociales desde tiempos prehispánicos. La materialidad de los mismos, como en cualquier construcción maya, respondería al estamento del usuario y su consecuente localización. Mientras que aquellos ubicados en la periferia de las ciudades o en asentamientos de carácter rural se construirían con sencillos sistemas 
y materiales perecederos, los pertenecientes a la élite, ubicados en el corazón de la ciudad, presentarían mayor resistencia y durabilidad gracias al empleo de técnicas más avanzadas y materiales de mayor calidad.

La mayor parte de ejemplos arqueológicos que han llegado hasta nuestros días son muestra del empleo de técnicas constructivas avanzadas y de materiales de mayor calidad, resistencia y durabilidad, generalmente asociados con la élite. Por tanto, este tipo de construcciones dejarían de levantarse a raíz del colapso cultural maya. Esta circunstancia, sumada al alejamiento de las autoridades coloniales de la práctica del temascal (figura 2), habría supuesto la sola pervivencia de una tipología de baño de vapor de carácter doméstico — casi clandestino- cuya construcción, más humilde, en muchas ocasiones incluso efímera, difiere formalmente de la mayor parte de los restos arqueológicos hallados y, sin embargo, se asemeja al temascal contemporáneo.

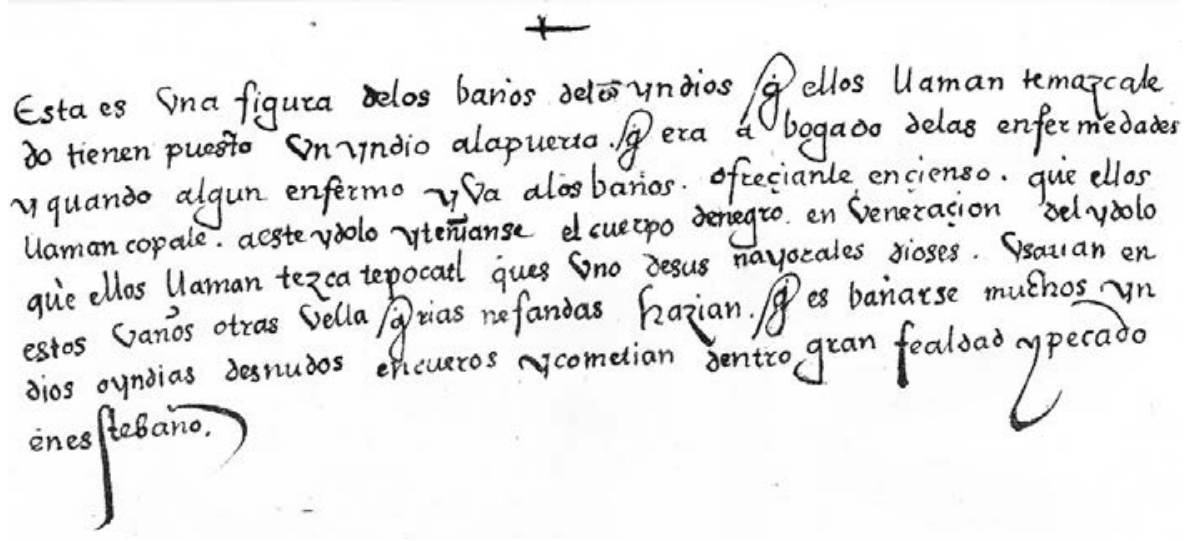

Figura 2. Códice Magliabecchiano, lámina 76 (trasera).

Dicha circunstancia ha provocado una continua confusión en la terminología empleada en la bibliografía específica, que conviene matizar. Ciertos autores, al identificar el temascal elitista con las grandes urbes prehispánicas, asocian por contraposición el baño de "estilo campesino" a las áreas rurales (Groark, 1997: 8). Sin embargo, existieron también temascales populares en la periferia de las grandes urbes. Por consiguiente, parece más apropiado adoptar la terminología de temascal popular o doméstico en contraposición al elitista, respondiendo a un uso por parte de la población llana, con independencia de su ubicación urbana o rural.

Por otro lado, debe tratarse la cuestión geográfica, puesto que es cierto que en la actualidad el empleo del baño de vapor predomina en zonas más altas y frescas, como la altiplanicie mexicana y guatemalteca, donde es todavía común 
encontrar estructuras de este tipo que siguen siendo utilizadas por comunidades locales (Alcina et al., 1980: 100-102).

Fundamentalmente el temascal sigue siendo utilizado para la higiene personal cotidiana y ciertos tratamientos terapéuticos, aunque su función ceremonial no ha desaparecido por completo. El baño de vapor implica un concepto de limpieza corporal "casi extinguido" (González, 2007: cap. 2, 7) que se dirige desde el interior hacia el exterior. La sudoración en un ambiente cálido y húmedo, como el que se genera en el temascal, permite la expulsión de toxinas internas, eliminando todas aquellas sustancias que el cuerpo considera innecesarias. Además, la cálida atmósfera del baño conlleva una serie de beneficios terapéuticos implícitos. El calor no sólo reactiva el torrente sanguíneo, sino que, al comportarse como vasodilatador, actúa como calmante, disminuyendo la rigidez articular y muscular. Es conocida la estrecha relación entre el temascal y los cuidados de la mujer durante el embarazo y parto, de la que derivan múltiples ritos ceremoniales asociados con deidades femeninas que actuaban como protectoras o dueñas del baño de vapor. Esta función ceremonial es la que más ha evolucionado a lo largo del tiempo, adaptándose a los devenires históricos, en particular desde que los colonizadores iniciaron el proceso de evangelización y las manifestaciones tenidas por paganas se debían realizar de modo clandestino o sincretizarse con las cristianas. Hoy en día, el temascal sigue siendo un elemento de elevada carga simbólica que se considera vínculo con la tierra natal, y por tanto a él debe volver el enfermo para renacer desde la purificación (Ichon, 1973: 297).

La preparación del espacio inicia horas antes del baño, al comenzar la combustión de leña en el hornillo, que en los temascales contemporáneos suele ser un anexo a la sala principal. Este fuego permite, además, que la cámara de baño vaya calentándose poco a poco. Cuando el fuego está listo y las piedras suficientemente calientes, se cierra el hornillo con barro o piedras, para que no se produzcan fugas de calor. Si existen respiraderos, se abren para eliminar el humo que pudiera quedar en la sala de baño, y de inmediato se vuelven a cerrar. En este punto se convoca a los bañistas, que se dispondrán sobre las banquetas, o bien sobre petates u hojas en el suelo.

El agua se vierte sobre las piedras a alta temperatura, generándose de inmediato el vapor. Dependiendo de la edad del usuario, se entiende que puede permanecer en el interior bajo estas condiciones durante un cierto tiempo. Los bañistas pueden proveerse de hierbas medicinales para "hojearse", o de tinajas de agua para refrescarse. Una vez concluido el proceso, y dependiendo de la tradición del lugar, uno puede bañarse con agua para aclararse el sudor, o bien cubrirse con una sábana para protegerse hasta que el cuerpo se recupere.

La arquitectura del temascal actual es de carácter humilde, correspondiente a una población que basa su economía en la agricultura y la ganadería y construye sus edificaciones a partir de los materiales disponibles. Por lo común el temascal es de uso doméstico, y se construye en áreas aledañas a la residencia. Tan sólo en algunas pocas poblaciones se cuenta con un baño de uso comunal, de dimensio- 
nes mayores a los familiares, puesto que da servicio a toda la población. En estos poblados todavía perdura el oficio del "temascalero", personaje que se encarga de prender el fuego y calentar adecuadamente el lugar.

\section{Identificación de casos de estudio}

Para la selección de los casos de estudio se emplean las clasificaciones más exhaustivas publicadas, que son las realizadas por Ichon (1977), Alcina et al. (1980), Groark (1997) y Child (2007). Estos listados son un compendio de aquellas construcciones identificadas como temascales, de los que se tiene conocimiento bien por referencias bibliográficas bien mediante comunicaciones personales. Los autores incluyen en ocasiones ciertas consideraciones personales al respecto, que matizan los datos publicados. El propio análisis de estos elencos es fundamental, puesto que se han detectado diversos errores heredados, así como suposiciones que derivan en certezas con el paso de las citas.

Alain Ichon (1977: 203-204), con motivo del hallazgo de un posible temascal en Los Cimientos-Chustum (Guatemala), cita como antecedentes de su investigación un total de 18 edificios, elaborando de esta manera el primer compendio de temascales mayas prehispánicos. Cada ejemplar viene acompañado por la referencia bibliográfica que identifica al edificio como tal o, en su defecto, se indica que se trata de una comunicación personal. El autor recalca que la clasificación se ha realizado teniendo en cuenta las consideraciones establecidas por Satterthwaite (1952: 20): "Podríamos asumir con certeza que los baños de vapor de los antiguos mayas deben mostrar al menos los complejos BC", es decir, un temascal ha de presentar al menos ciertos rasgos adecuados para producir y retener el calor/vapor. Entre ellos aparecen los ocho ejemplares de Piedras Negras, dos en Chichén Itzá, uno en Palenque, otro en Tikal (comunicación de Christopher Jones), uno en Uaxactún (comunicación de Edwin Shook) y uno más en Finca El Paraíso. En su texto, Ichon descarta como dudosos o improbables los dos temascales de Quiriguá descritos por Morley y aquél de El Chile, mencionado por Sattherthwaite, así como la posibilidad planteada por Puleston (1965) de que los chultunes de Uaxactún y Tikal fuesen empleados como tales. Finalmente menciona un posible temascal, todavía sin excavar, en Iximché.

Apenas tres años más tarde, Alcina et al. (1980: 104-109) recogen un total de 21 ejemplares ubicados en 12 asentamientos. Es decir, introducen tres nuevos ejemplares, y se aporta como nuevo dato el periodo al que pertenecen. Éstos son el baño de vapor en San Antonio (Chiapas), un posible temascal en Zacualpa y el propio de Agua Tibia (ambos en Guatemala), objeto de estudio principal de su trabajo. Los ejemplares que Ichon (1977) plantea como improbables, como el del El Chile o los chultunes de Uaxactún, no aparecen en el listado, a excepción del caso de Quiriguá, que se justifica con una referencia a los textos de Morley (1936a). Curiosamente, aquellos ejemplares incluidos a partir de una comunicación 
personal, como Tikal, Iximché y Uaxactún, remiten al trabajo de Ichon. Es decir, a medida que se publican los sucesivos elencos, se consolidan ciertas inclusiones para las que no existe una referencia bibliográfica que permita contrastar dichos datos. Sin embargo, la aportación más relevante de este trabajo no es la clasificación apenas presentada, sino la aparición del concepto de temascal rural en contraposición al monumental, que trataremos más adelante.

Más tarde, la clasificación de Groark (1997: 9-10) amplía el compendio a 144 temascales ubicados en 31 sitios. No se elimina ninguno de aquellos citados por Alcina et al., aunque el autor señala con un signo de interrogación ciertos ejemplares cuya identificación es cuestionable. El aumento de ejemplares podría derivar de los lógicos avances en las excavaciones arqueológicas, y en cierta manera es así, puesto que resulta fundamentalmente de ampliar el marco temporal abarcando ejemplares del Posclásico Tardío y la época colonial.

En particular, el estudio analiza el caso de Coapa y Coneta, dos sitios arqueológicos del periodo colonial ubicados junto al Camino Real de Chiapas, que presentan un elevado porcentaje de temascales de estilo rural. Y no sólo destaca el gran número -83 y 16 respectivamente-, sino que, además, éstos muestran ciertas similitudes con baños de vapor del Posclásico Tardío, como los localizados en Los Encuentros. Estos datos se interpretan como confirmación de la ya inferida continuidad de la tradición del baño de vapor de carácter doméstico desde época precolombina hasta el periodo colonial, o incluso hasta nuestros días (Groark, 1997: 14).

Como ejemplares precolombinos, el elenco incluye el caso de Dzibilchaltún, con un ejemplar del Preclásico y otro del Posclásico; tres ejemplares del Clásico Temprano en Chiapa de Corzo y uno en Ocozocoautla. Del periodo Clásico destaca la referencia a Joya de Cerén, un caso fundamental por sus particulares condiciones de conservación. Tal y como lo hacen Alcina et al., incluye los dos de Quiriguá ofrecidos por Morley y marca como dudosos los ejemplos de Iximché y Zacualpa. También cuestiona los dos casos en Tikal y la olvidada cita en El Chile. Las referencias del Clásico Tardío incluyen los ocho de Piedras Negras y los de Agua Tibia, Finca El Paraíso, Palenque y San Antonio (para estos dos últimos sitios se añade un nuevo ejemplar). Agrega nuevas referencias en sitios arqueológicos no citados previamente: dos en Toniná y en Los Cimientos, y uno en Los Cerritos. Como temascales posclásicos mantiene los dos casos de Chichén Itzá, el dudoso caso de Iximché y el ya nombrado de Dzibilchaltún. Como pertenecientes al Posclásico Tardío añade a la referencia de Los Cimientos-Chustum registrada por Ichon, los casos de Cerro Víbora, El Limón, Nueva Independencia, Pueblo Viejo y los ya mencionados de Los Encuentros. Tres casos aparecen sin datar: dos en Las Margaritas y uno en El Amolillo.

Finalmente, el estudio de Child (2007) reduce de nuevo el ámbito temporal y abarca sólo hasta el Posclásico. Se introduce un ejemplo más del Preclásico en Cuello, más una serie de referencias correspondientes al Clásico que incluye los dos ejemplares en Becán, Yaxchilán y Comalcalco, más uno en Calakmul, Chiapa de Corzo, Edzná, Malpasito y Nakum. En total 41. 
Es decir, si el ámbito temporal se delimita previo a la conquista, el resultado obtenido es de un total de 45 temascales, de los cuales cerca de un $25 \%$ han sido incluidos aun manifestándose dudas razonables en cuanto a su identificación. Un $78 \%$ de los casos se clasifican como urbanos o de élite, mientras que el porcentaje restante se identifica como rural-campesino.

\section{Documentación de casos}

El proceso de documentación de cada ejemplar se inicia a partir de la bibliografía facilitada en los elencos examinados en el apartado anterior. En una segunda fase se acude a los informes arqueológicos, en su mayoría inéditos, para tratar de localizar la información específica que se precisa para este estudio. Por desgracia, el manejo de estos datos no es siempre factible. Finalmente, en la medida de lo posible, se contacta con los arqueólogos responsables de dichas excavaciones.

\section{Sistematización de la información}

La abundante documentación recopilada se sistematiza en fichas elaboradas ex profeso que permiten clasificar la información específica. Éstas son de tamaño A4 horizontal, a dos caras, y se componen de tres secciones: documentación gráfica, síntesis y descripción (figura 3).

Satterthwaite fue pionero en clasificar los rasgos arquitectónicos vinculados con la función del temascal, y aclarar la terminología empleada al respecto. Para ello tomó como base cinco casas de baño de vapor contemporáneas ${ }^{4}$ y las comparó. Como resultado obtuvo una serie de características, descritas con detalle, que ordenó en cuatro grupos: drenaje de la estancia, retención del calor/vapor, producción del calor/vapor y elementos menores de carácter general, como banquetas o dependencias auxiliares.

En primera instancia, el análisis aquí propuesto toma como referencia dicha clasificación. Sin embargo, durante el desarrollo de los trabajos, surgió una serie de cuestiones que suscitaron ciertas modificaciones en aras de facilitar el estudio comparativo. En primer lugar, se opta por diferenciar los rasgos arquitectónicos vinculados con la producción/retención de calor y la producción de vapor, asociando las cuestiones relativas al fuego con el primero y al agua con el segundo. Esto deriva en la supresión del drenaje como categoría, que pasa a considerarse un rasgo vinculado a la generación de vapor y a la posterior condensación. Finalmente, se considera oportuno diferenciar también entre producción y retención, puesto que las estrategias arquitectónicas diseñadas para satisfacer dichas funciones se distinguen con claridad. Por consiguiente, la clasificación de rasgos

\footnotetext{
${ }^{4}$ Los temascales comparados son el de S. Martín de Teotihuacan (México), Tepoztlán (México), Chichicastenango 1 (Guatemala), Milpa Alta 1(México) y Aguacatán (Guatemala) (Satterthwaite: 1952).
} 


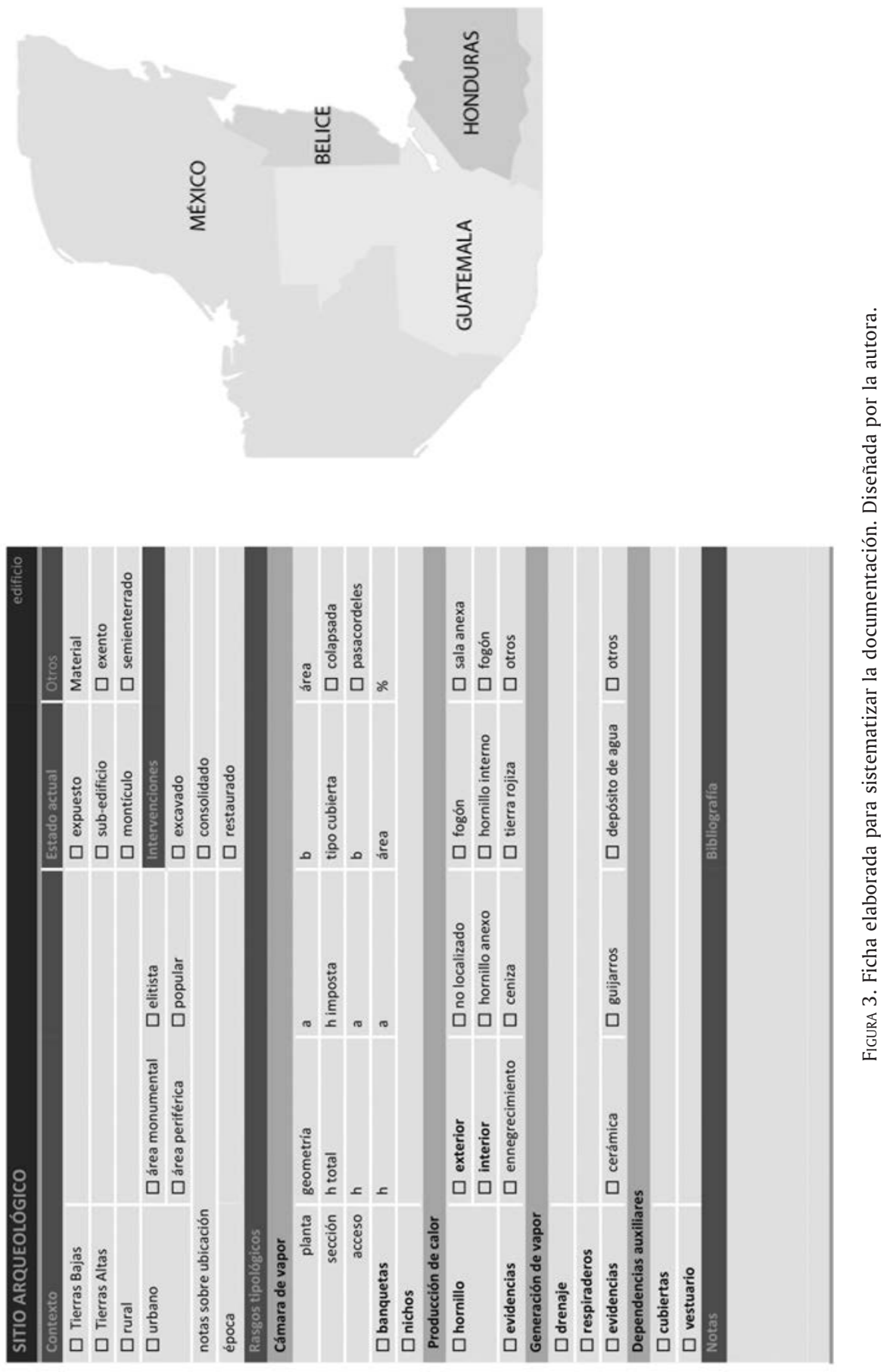


arquitectónicos vinculados a la función del temascal queda de la siguiente manera: cámara de vapor, elementos asociados a la producción de calor, elementos asociados a la producción de vapor, y dependencias auxiliares. A continuación discutiremos la correspondiente idoneidad/necesidad de dichos elementos en la identificación de estas construcciones.

\section{Cámara de vapor}

\section{Dimensiones y geometría}

El elemento central del temascal es la sala de vapor, donde los usuarios se ubican para beneficiarse de la elevada concentración de calor. Se trata de una estancia de dimensiones reducidas, ya que la dificultad de reunir las condiciones adecuadas de temperatura aumenta a medida que lo hace el área que delimitan sus muros. Es decir, las dimensiones son menores de lo que sería común en caso de una ocupación cotidiana (Satterthwaite, 1952: 14). Por este motivo también el techo se ubica a una altura menor de lo habitual, y se diseña de modo que se eviten posibles escapes de vapor. En algunos casos se coloca también un sobre-techo que contribuiría a este fin. La planta de la sala de vapor no tiene una forma predeterminada, sino que, por lo general, depende del sistema constructivo empleado.

El acceso desde el exterior se produce mediante un vano estrecho y de baja altura, que prácticamente obliga a la persona a entrar a gatas (Cresson, 1938: 92). La cámara puede estar sobre el terreno o ser total o parcialmente subterránea (Alcina et al., 1980: 112). Estas características contribuyen a mantener las condiciones adecuadas en la sala durante el tiempo necesario para el baño.

Banquetas

En el interior pueden disponerse banquetas que permiten que el bañista se ubique a mayor altura, y por tanto más cerca de la principal acumulación de vapor (Satterthwaite, 1952: 16). Estos elementos pueden ser parte de la propia arquitectura o tratarse de mobiliario.

Nichos

En ocasiones aparecen nichos en los muros, donde se puede colocar ofrendas a las deidades del baño.

\section{Producción de calor}

Hornillo

El lugar donde se prende el fuego, y a partir del cual se generará el calor suficiente para calentar las piedras y producir así el vapor de agua necesario para el 
baño, se denomina hornillo, hogar o fogón. Se trata de un elemento fundamental para el funcionamiento del temascal. De hecho se afirma que "si no hay al menos un hornillo, no puede ser un temascal" (Satterthwaite, 1952: 14).

En los temascales contemporáneos este hornillo suele ser una construcción anexa a la principal, rellenándose la cara de contacto con piedra volcánica apilada verticalmente a modo de cortina. La función de este elemento es almacenar calor suficiente para producir el vapor necesario mientras el bañista se encuentra en el interior y el fuego ya se ha consumido. Por ello se emplea material de carácter poroso que permite dicha acumulación, y que, al rociarse con agua, genera vapor (Cresson, 1938: 94).

En los temascales arqueológicos, el hornillo suele construirse en el interior de la sala de vapor, o simplemente delimitado de algún modo con sillares dispuestos alrededor. Si estos hornillos interiores actuaron como tales, o sencillamente eran el lugar de depósito de unas piedras calentadas en el exterior, es un debate abierto. Las evidencias arqueológicas muestran restos de ceniza y ennegrecimiento propios de la exposición a altas temperaturas, pero no podemos constatar si son suficientes para declarar que el fuego se hizo en el interior.

\section{Respiraderos}

Se prefiere la denominación de respiradero frente a la de ventilador, puesto que se trata de aberturas de dimensiones mucho más reducidas que pueden ser bloqueadas fácilmente. Su misión podría ser la de avivar el fuego cuando fuese necesario, eliminar el humo antes del baño o ventilar la estancia una vez concluido el mismo, pero no resultan esenciales para su funcionamiento.

Éstos facilitan la ventilación necesaria e incluso ayudan a avivar el fuego gracias a la corriente de aire que se establece. También contribuyen a la salida de humo acumulado previa entrada de los bañistas, e incluso del vapor sobrante si se requiere. Puede darse también que la corriente que se genera entre la puerta y el resquicio entre techumbre y muros sea suficiente para ejercer esta función.

\section{Generación de vapor}

El vapor necesario se produce mediante el vertido de agua sobre unas piedras o pantallas de piedra volcánica calentadas previamente con un intenso fuego.

\section{Drenaje}

El estudio del uso del temascal contemporáneo indica que el agua que se emplea para generar el vapor no necesita ser evacuada, precisamente porque sufre un cambio de estado y al volverse a condensar no conlleva excesivos problemas. En efecto, el único caso en el que se presentan vías de desagüe es en aquellas regiones en las que la tradición recomienda proceder a un baño de agua pura tras la sudoración, y por tanto la cantidad de líquido empleado es mucho mayor (Alcina et al., 1980: 112). 
Generalmente, el suelo de la estancia tiene ya una pendiente que permite reunir el agua para poder evacuarla (Satterthwaite, 1952: 11). Además, existen otros elementos que permiten la salida del agua, desde sencillos huecos abiertos en el muro hasta pasos de drenaje. Estas canalizaciones se sitúan a nivel más bajo del piso del temascal. Satterthwaite remarca la diferencia entre aquellos que tienen el desagüe como función exclusiva, y los que sirven como pasaje y facilitan la entrada al temascal a través del pequeño vano, prolongándose una distancia considerable tanto hacia dentro como hacia fuera del acceso (1952: 12).

\section{Dependencias anexas}

$\mathrm{Al}$ exterior del temascal es frecuente encontrar techumbres o espacios de cobijo en los que los usuarios se sitúan tras el baño de vapor para recuperarse. En ciertas ocasiones, puede aparecer una pieza dedicada a vestuario.

En el caso de los temascales comunales, este espacio anterior a la cámara de vapor es donde los usuarios se desvisten y dejan sus ropas para entrar a la sala. En ese mismo lugar reposan tras el baño, e incluso, si se recomienda, pueden bañarse con agua pura para eliminar el sudor.

\section{Materiales de construcción}

Los materiales que se emplean en la construcción del temascal dependen básicamente de los recursos disponibles, y por ello se utilizan sobre todo madera y adobe, fáciles de trabajar pero de durabilidad media (Ajxup, 1979: 43; Tyrakowsky, 2007: 74). Menos frecuente es el empleo de piedra caliza, mucho más duradera.

En los últimos años se ha popularizado el empleo de bloques de hormigón prefabricados, puesto que es un material relativamente económico y agiliza el proceso de construcción en comparación con otros métodos tradicionales. En el caso de los "toritos" o temascales desplazables, se emplean cañas para crear la estructura flexible semiesférica, que se recubre con huano u otro tipo de vegetación trenzada sobre la estructura.

\section{Análisis}

En la primera fase se descartan aquellos casos cuyas fichas, al menos por el momento, quedan incompletas por no disponerse de suficiente información o en caso de que ésta resulte difícilmente contrastable. A los efectos del presente estudio, resulta también imprescindible que el estado de la construcción permita un análisis arquitectónico, $\mathrm{o}$, al menos, pueda generar documentación gráfica suficiente para que pueda realizarse. Sirva como ejemplo el caso de Toniná, sobre el que el propio Taladoire (1975: 266) admitía que "el complejo estaba demasiado 
destruido como para ser identificable". Estos ejemplares son objeto de un análisis paralelo, y aunque los resultados no pueden ser concluyentes, sí ofrecen interesantes aportaciones al estudio. El caso de Toniná, por ejemplo, abre el debate sobre la posible vinculación de los temascales con los juegos de pelota, cuestión que se incorpora al análisis del resto de ejemplos.

Finalmente, se contabiliza un total de 18 casos de estudio completos: Estructura 605-2F de Dzibilchaltún, 1-11aㅗ de Chiapa de Corzo, AV:R 7-8 de Uaxactún, 10L-223-2b de Copán, 3C de Zacualpa, 9 de Joya de Cerén, 5E-22 de Tikal, 1B-2 y 1B-3-1을 de Quiriguá, temascal de Agua Tibia, P7-1ํㅡ, N-1-1ํㅡ, S-19, 0-4 de Piedras Negras, 26 de Nakum y 3C15-anexo sur y 3E3 de Chichén Itzá (figura 4).

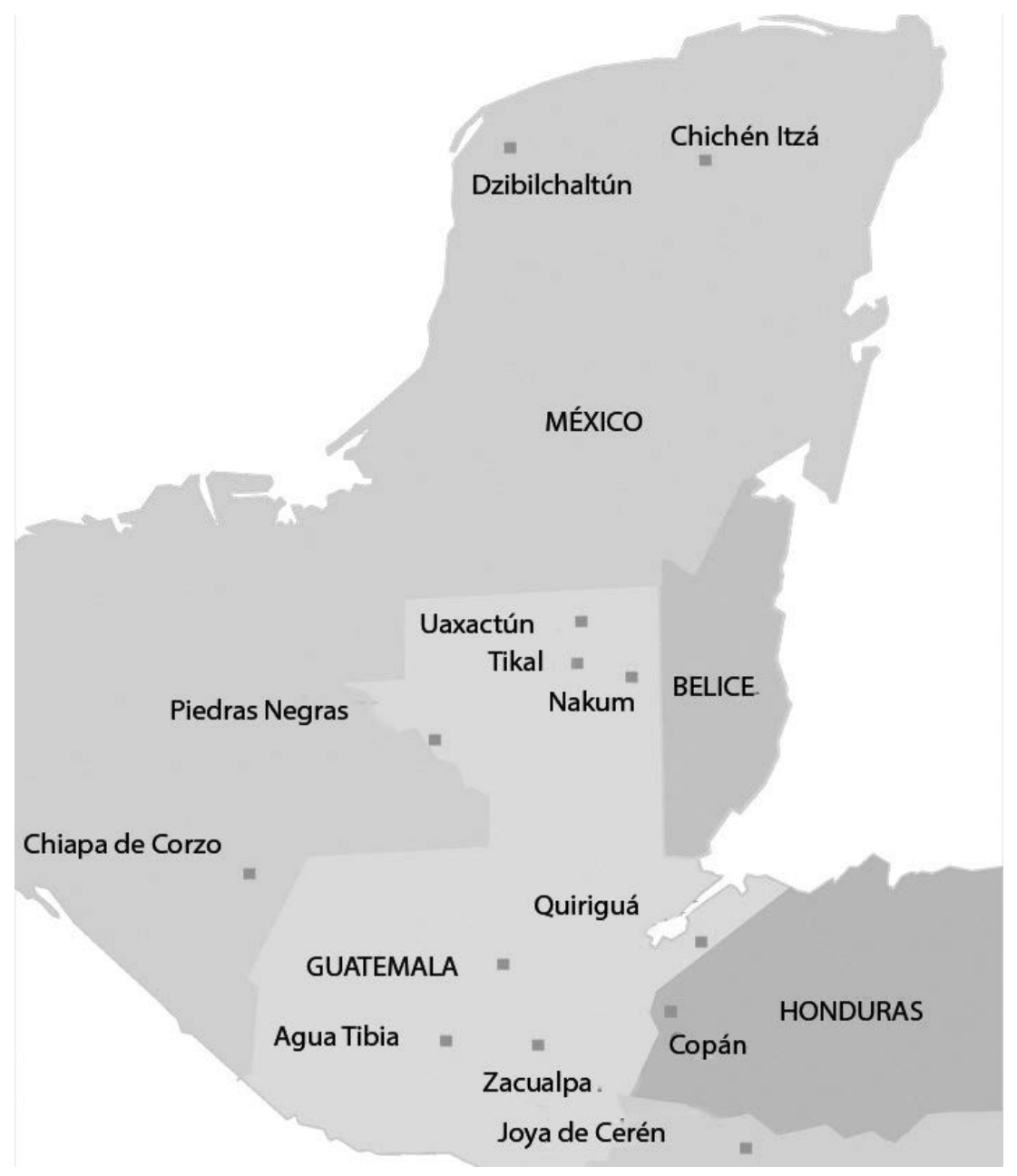

FIGURA 4. Ubicación de los temascales analizados en el área maya. Realizado por la autora. 
La mayoría de los baños de vapor que conforman el presente estudio se ubica en Tierras Bajas, a excepción de los de Zacualpa y Agua Tibia. Mientras que los ejemplos de Agua Tibia y Joya de Cerén pertenecen a asentamientos de carácter rural, los demás son urbanos y, salvo los de Zacualpa y Dzibilchaltún, se ubican en áreas monumentales y debieron servir a la élite (tabla 1).

\begin{tabular}{|c|c|c|c|c|c|c|c|}
\hline \multirow{3}{*}{ Contexto } & \multicolumn{2}{|c|}{ Ubicación } & \multicolumn{3}{|c|}{ Categoría } & \multicolumn{2}{|c|}{ Otros } \\
\hline & & & & Urbano & & & \\
\hline & T. Altas & T. Bajas & Rural & Elitista & Popular & Exento & Estancia \\
\hline Dzibilchaltún 605-2F & & $\mathrm{x}$ & & & $\mathrm{x}$ & $\mathrm{x}$ & \\
\hline C. de Corzo, 1J1a & & $\mathrm{x}$ & & $\mathrm{x}$ & & $\mathrm{x}$ & \\
\hline Uaxactún AV R7-8 & & $\mathrm{x}$ & & $\mathrm{x}$ & & $\mathrm{x}$ & \\
\hline Copán 10L-223-2b & & $\mathrm{x}$ & & $\mathrm{x}$ & & & $\mathrm{x}$ \\
\hline Zacualpa 3C & $\mathrm{x}$ & & & & $\mathrm{x}$ & $\mathrm{x}$ & \\
\hline Joya de Cerén 9 & & $\mathrm{x}$ & & & $\mathrm{x}$ & $\mathrm{x}$ & \\
\hline Tikal 5E-22 & & $\mathrm{x}$ & & $\mathrm{x}$ & & $\mathrm{x}$ & \\
\hline Quiriguá 1B-2 & & $\mathrm{x}$ & & $\mathrm{x}$ & & & $\mathrm{x}$ \\
\hline Quiriguá 1B-3-1ํㅡㅁ & & $\mathrm{x}$ & & $\mathrm{x}$ & & & $\mathrm{x}$ \\
\hline Agua Tibia & $\mathrm{x}$ & & $\mathrm{x}$ & & & $\mathrm{x}$ & \\
\hline Piedras Negras P7 & & $\mathrm{x}$ & & $\mathrm{x}$ & & $\mathrm{x}$ & \\
\hline Piedras Negras N-1 & & $\mathrm{x}$ & & $\mathrm{x}$ & & $\mathrm{x}$ & \\
\hline Piedras Negras S-9 & & $\mathrm{x}$ & & $\mathrm{x}$ & & $\mathrm{x}$ & \\
\hline Piedras Negras 0-4 & & $\mathrm{x}$ & & $\mathrm{x}$ & & $\mathrm{x}$ & \\
\hline Nakum, edificio 26 & & $\mathrm{x}$ & & $\mathrm{x}$ & & $\mathrm{x}$ & \\
\hline Chichén Itzá 3C15 & & $\mathrm{x}$ & & $\mathrm{x}$ & & $\mathrm{x}$ & \\
\hline Chichén Itzá 3E3 & & $\mathrm{x}$ & & & & $\mathrm{x}$ & \\
\hline
\end{tabular}

TABLA 1. Estudio de cámara de vapor.

Todos los casos pertenecen al periodo Clásico, a excepción de Dzibilchaltún, que es del Preclásico o Formativo, y los de Chichén Itzá, que son del Posclásico. Esta circunstancia nos permite reflexionar acerca de la cotidianeidad del uso del temascal en los diferentes periodos así como analizar el considerable aumento de estas construcciones hacia finales del Clásico —especialmente en sitios como 
Piedras Negras-, quizá vinculado con posibles influencias externas o asociaciones con un uso ceremonial que aumentaron el interés por el ritual del baño de vapor. Estas construcciones clásicas presentan una mayor uniformidad en sus rasgos y aumentan su complejidad arquitectónica a medida que nos acercamos al Posclásico, en especial en cuanto a dependencias anexas se refiere.

Los casos de Copán y Quiriguá resultan muy particulares por no tratarse de edificios exentos sino de estancias pertenecientes a un complejo. El ejemplo de Copán presenta unas dimensiones a priori adecuadas, un hornillo para producir calor, evidencias de ceniza e incluso un canal de drenaje. Sin embargo, la falta de delimitación de la estancia — no hay evidencia de cerramiento sur- no permitiría la retención del vapor de agua. Este mismo argumento podría ser empleado para los casos de Quiriguá, en los que la aparición de guijarros ennegrecidos hizo suponer que dichas estancias pudieron haberse empleado puntualmente para la preparación de un baño de vapor aun no existiendo tan siquiera evidencia de hornillo.

El análisis que se presenta a continuación se realiza teniendo en consideración las diferencias tipológicas entre las distintas categorías de temascal ya presentadas previamente y las circunstancias específicas que se han expuesto.

\section{Cámara de vapor}

La dificultad de alcanzar las condiciones adecuadas para el baño de vapor radica, en gran medida, en las dimensiones internas de la cámara de vapor, que son menores a las que serían habituales en caso de una ocupación normal. El acceso también es de altura y anchura comedidas, persiguiendo el mismo objetivo. Estas dimensiones son muy variables, atendiendo al carácter del temascal. Si es doméstico, como sería el de Zacualpa, su dimensión es de $2 \mathrm{~m}^{2}$, donde apenas podría bañarse una persona. En cuanto a los destinados a las élites, las dimensiones de los ejemplares considerados oscilan entre $8 \mathrm{~m}^{2}$ y $16 \mathrm{~m}^{2}$ de área y una altura entre 2.5 y 3.5 m (figura 5$)$.

Se ha detectado la presencia de pasa-cordeles en las jambas de dicho acceso en los casos de Uaxactún, en el 3E3 de Chichén Itzá y en el 26 de Nakum; sistema que impediría la salida prematura del vapor obtenido.

La jerarquización del espacio mediante la división de alturas a partir de banquetas no sólo permite que el usuario se ubique en una posición más cercana a la acumulación de vapor, sino que, además, distingue el área de movimiento de aquella de reposo. La disposición de las mismas, generando un corredor desde el hornillo hasta el acceso, ha sido considerada como una posibilidad de desaguie, dado que los ejemplos presentan una ligera pendiente hacia el exterior. El porcentaje de área ocupada por banquetas es elevado en comparación con cualquier otro tipo de estancia palaciega. En el caso de temascales populares, no se han localizado banquetas. Sin embargo, es posible que éstas fueran de carácter efímero. 


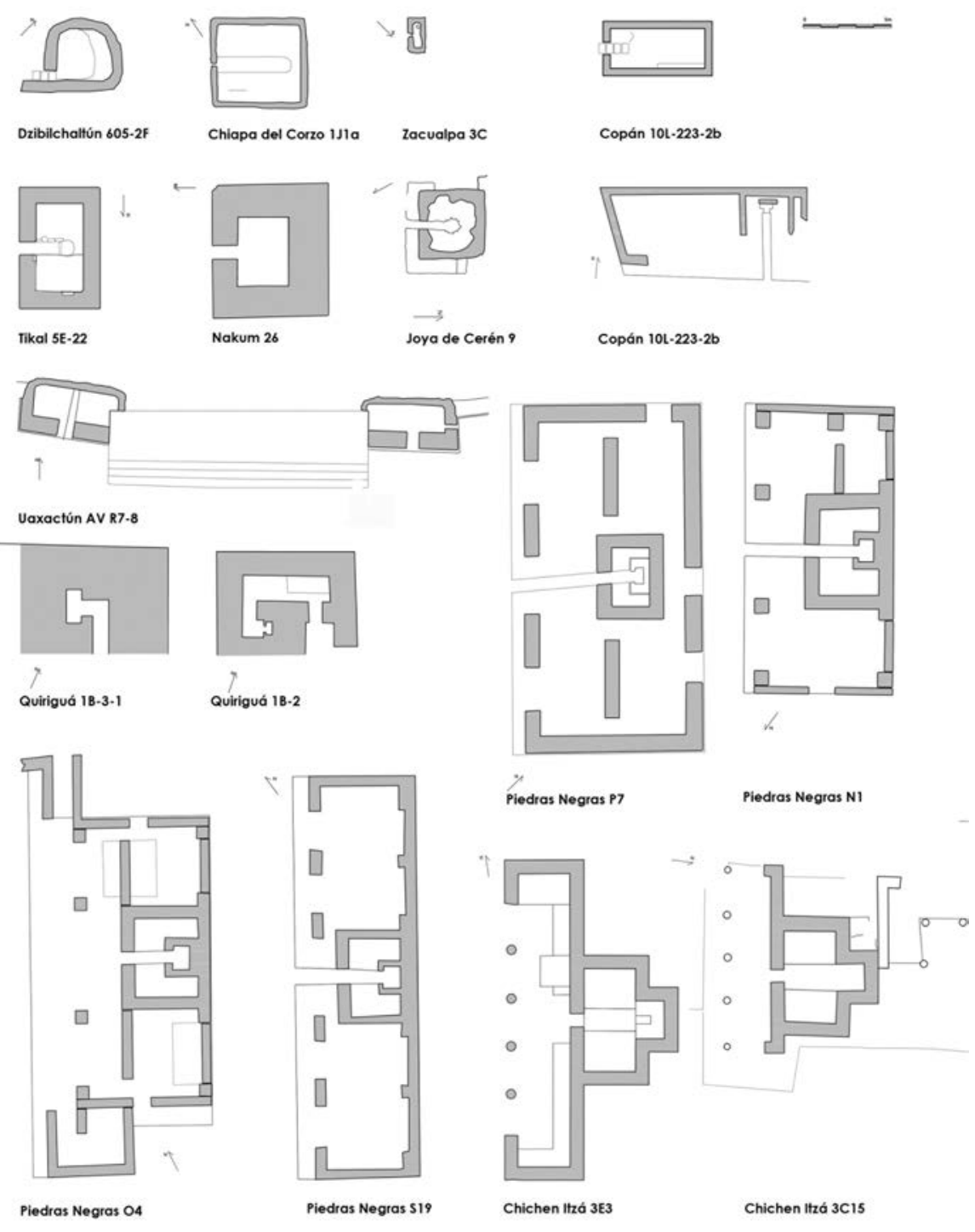

FIGURA 5. Plantas de los temascales analizados realizadas por la autora a partir de la documentación recabada. Dzibilchaltún (Andrews y Andrews, 1980), Chiapa de Corzo (Lowe y Agrinier y Lowe, 1960: 34-36 y Mason, 1935), Uaxactún (Smith, 1950 y Proskouriakoff, 1946: 111-133), Copán (Cheek y Spink, 1986), Zacualpa (Wauchope, 1948), Joya del Cerén (Sheets, 1992 y MacKee, 1997), Tikal (Jones, 1996 y levantamiento arquitectónico propio), Quiriguá (Morley, 1936a, 1938; Sharer y Ahmore, 1979, y Sharer et al., 1983), Agua Tibia (Alcina et al.,1980), Piedras Negras (Sattherthwaite, 1952; Proskouriakoff, 1946; Child y Child, 2000, y 2001), Nakum (informes IDAEH y levantamiento arquitectónico propio) y Chichén Itzá (Ruppert, 1935, 1952; Morley, 1936b, y Tozzer, 1957). 
Los nichos, en los que en la actualidad se ubican figurillas pertenecientes a deidades relacionadas con el baño, no son usuales en este tipo de temascales. Tan sólo aparecen en P7 de Piedras Negras, pero no en el interior de la cámara de vapor, sino en el vestíbulo. El nicho en el interior del temascal de Nakum, hoy clausurado, debió servir como hornillo en sus primeros estadios constructivos (tabla 2).

\begin{tabular}{|c|c|c|c|c|c|c|c|c|c|c|}
\hline & \multicolumn{6}{|c|}{ Interior } & \multicolumn{3}{|c|}{ Vano } & \multirow[t]{2}{*}{ Nicho } \\
\hline & $\begin{array}{l}\mathrm{a}^{*} \\
(\mathrm{~m})\end{array}$ & $\begin{array}{l}\mathrm{b}^{*} \\
(\mathrm{~m})\end{array}$ & $\begin{array}{l}\text { área } \\
\left(\mathrm{m}^{2}\right)\end{array}$ & $\begin{array}{c}\% \\
\text { banq }\end{array}$ & $\begin{array}{l}\mathrm{h} \\
(\mathrm{m})\end{array}$ & $\begin{array}{l}\mathrm{h} \text { im- } \\
\text { posta }\end{array}$ & $\begin{array}{c}\mathrm{a} \\
(\mathrm{m})\end{array}$ & $\begin{array}{l}\mathrm{h} \\
(\mathrm{m})\end{array}$ & pc & \\
\hline $\begin{array}{c}\text { Dzibilchaltún } \\
605-2 \mathrm{~F}\end{array}$ & 2.95 & 2.80 & 8.26 & - & $i$ & $i$ & 0.95 & $i$ & & \\
\hline C. de Corzo, 1J1a & 4.70 & 4.50 & 21.50 & $81 \%$ & $i$ & $i$ & $i$ & $i$ & & \\
\hline Uaxactún AV R7-8 & 4.78 & 1.78 & 8.98 & - & $i$ & $i$ & 0.89 & $i$ & $\mathrm{x}$ & \\
\hline Copán 10L-223-2b & 5.35 & $i$ & $i$ & - & $i$ & $i$ & $i$ & & & \\
\hline Zacualpa 3C & 2.00 & 1.00 & 2.00 & - & $i$ & $i$ & $i$ & $i$ & & \\
\hline Joya de Cerén 9 & 3.45 & 3.45 & 12.00 & $75 \%$ & 2.05 & 1.30 & 0.45 & 0.80 & & \\
\hline Tikal 5E-22 & 5.14 & 2.75 & 14.14 & $83 \%$ & 3.20 & 2.15 & 0.76 & 1.55 & & \\
\hline Quiriguá 1B-2 & 4.89 & 1.45 & 7.09 & - & $i$ & $i$ & 0.77 & $i$ & & \\
\hline Quiriguá 1B-3-1ํㅡㅁ & 1.22 & 0.81 & 0.99 & - & 1.52 & $i$ & 0.56 & 0.76 & & \\
\hline Agua Tibia & 1.70 & 3.90 & 6.63 & - & $i$ & $i$ & 0.48 & $i$ & & \\
\hline Piedras Negras P7 & 3.30 & 2.20 & 7.26 & $60 \%$ & 2.70 & 1.30 & 0.77 & 1.10 & & \\
\hline Piedras Negras N-1 & 4.80 & 3.25 & 15.60 & $78 \%$ & $i$ & $i$ & 0.70 & 1.00 & & $\mathrm{x}$ \\
\hline Piedras Negras S-9 & 4.49 & 3.11 & 13.96 & $61 \%$ & $i$ & $i$ & 0.80 & 1.05 & & \\
\hline Piedras Negras 0-4 & 4.46 & 3.61 & 16.10 & $67 \%$ & $i$ & $i$ & 0.76 & $i$ & & \\
\hline Nakum, edificio 26 & 3.92 & 2.86 & 11.21 & $88 \%$ & 3.95 & 1.86 & 0.79 & 1.77 & $\mathrm{x}$ & $\mathrm{x}$ \\
\hline Chichén Itzá 3C15 & 5.10 & 2.90 & 14.90 & $73 \%$ & $i$ & 1.07 & $i$ & 0.75 & & \\
\hline Chichén Itzá 3E3 & 5.88 & 2.95 & 17.30 & $78 \%$ & 3.21 & 1.24 & 0.72 & 0.83 & $\mathrm{x}$ & \\
\hline
\end{tabular}

*Dimensiones aproximadas.

TABLA 2. Clasificación de temascales analizados. 


\section{Producción de calor}

\section{Hornillo}

Todos los ejemplos presentados se servían de un hornillo interior para la producción de calor, o al menos para el depósito de las piedras calentadas previamente en el exterior. El estuco y los sillares de dichas zonas presentan evidencias de haber sido sometidos a altas temperaturas; ennegrecimiento, hollín y cenizas son habituales.

Los casos de Piedras Negras y Chichén Itzá cuentan con hornillos claramente diferenciados; de hecho, en Chichén Itzá, a diferencia del resto, no se encuentra embebido en planta. En Tikal y Chiapa de Corzo, el hornillo apenas se delimita mediante sillares.

Podría aventurarse la existencia de un hornillo o cámara de combustión en el exterior del temascal, lo cual evitaría que el interior se ahumase. En tal caso las piedras habrían sido transportadas al interior una vez calientes. Sin embargo, no se han localizado casos de este tipo de edificaciones junto a evidencias efectivas de fuego.

\section{Respiraderos}

Tan sólo en el caso de 3E3 de Chichén Itzá se han localizado respiraderos propiamente dichos. Se trata de dos orificios protegidos por unas piezas especiales en forma de X que regularían la ventilación. En Nakum es posible que el hueco sobre el acceso realizase dicha función.

Los respiraderos podrían servir para avivar el fuego o eliminar el humo previo al baño o quizá simplemente para airear el vapor tras el baño.

\section{Generación de vapor}

Hemos visto que en los temascales el vapor se genera mediante el vertido de agua sobre piedras a elevada temperatura. Por este motivo, se esperaría localizar fragmentos de las vasijas empleadas para el almacenamiento de agua. El estudio de los informes arqueológicos ha permitido constatar que tal fue el caso en Tikal, Nakum o Chiapa de Corzo. No obstante, sólo en el último sitio se localizaron guijarros ennegrecidos en el hornillo.

Sobre la ya discutida necesidad de drenaje, como se ha sugerido antes, éste podría ser el corredor de acceso en cualquiera de los ejemplos. En el caso de 3C15 de Chichén Itzá se conecta a un canal exterior de desaguie. También en Chiapa de Corzo, donde el acceso no se ha localizado, las banquetas configuran un corredor que desemboca en una salida de aguas al exterior.

El empleo de agua para un baño tras la sudoración no es punto común en el desarrollo de esta tradición. Por ello, no se considera condición sine qua non la cercanía a un depósito de agua. Sin embargo, sabemos que junto a 3C15 se lo- 


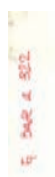

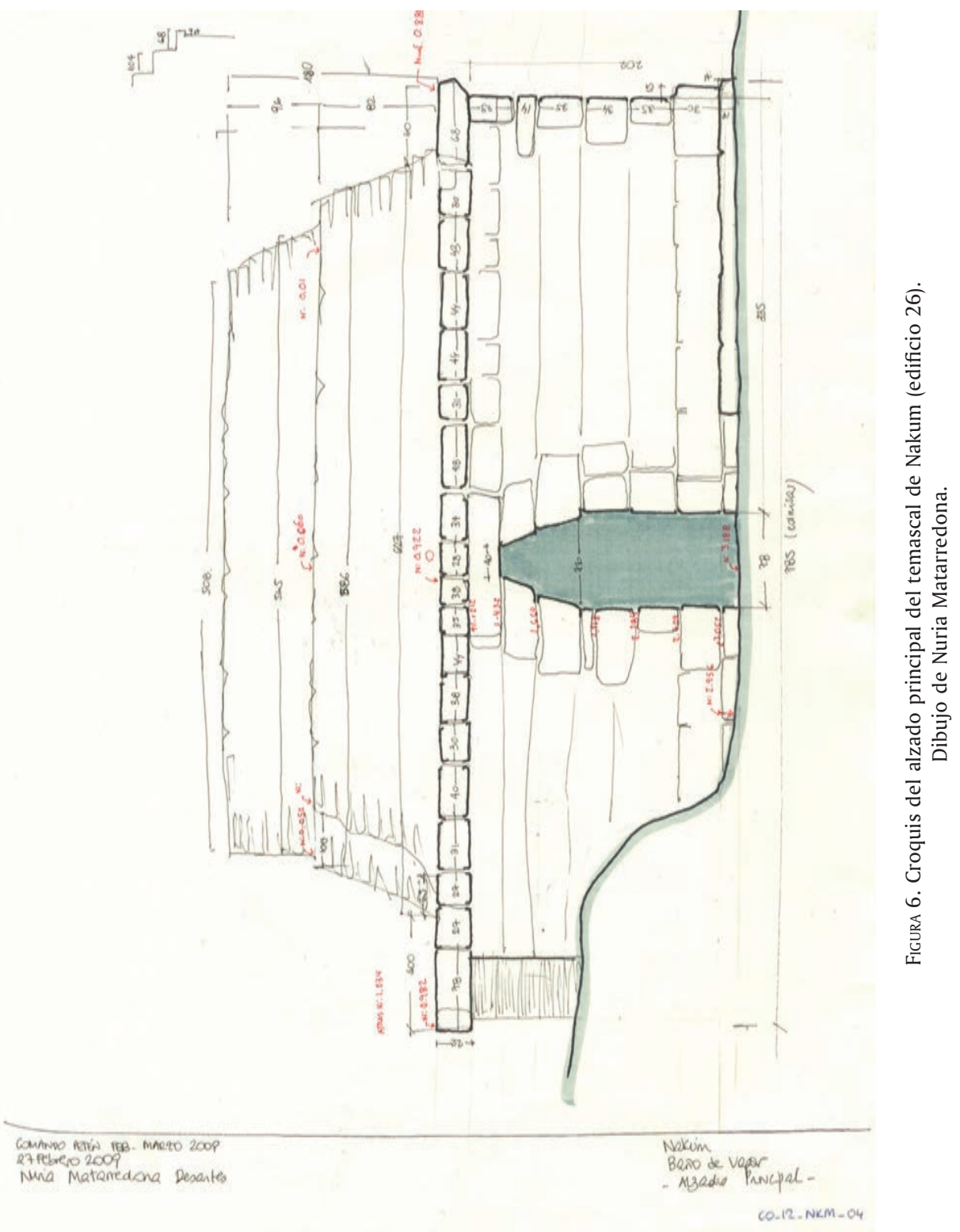


caliza una cisterna con profundidad de $1.25 \mathrm{~m}$ y diámetro de $1.52 \mathrm{~m}$, conectada precisamente al canal de drenaje, y que en el caso de P7 en Piedras Negras, el espacio sobre la cámara de vapor podría haber funcionado como un depósito para recoger agua de lluvia (figura 6).

Entre los casos escogidos para el estudio comparativo no se conocen relaciones con otras estructuras de almacenamiento de agua, pero destaca la vinculación de 1D1 de Chichén Itzá con el Cenote de los Sacrificios, aunque no se ha podido determinar su función como temascal.

\section{Dependencias anexas}

La exposición a las elevadas temperaturas durante el baño de vapor conlleva trastornos en la tensión corporal de los individuos que pueden conducir al mareo e incluso el desvanecimiento. Por ello, se aconseja que los bañistas reposen un tiempo tras el baño para recuperarse. En algunos casos, estos espacios son imponentes piezas construidas junto a la cámara de vapor, como ocurre en las galerías de Chichén Itzá o los vestuarios de Piedras Negras, en los que se disponen banquetas. En el ejemplo de Tikal se tiene constancia de una hendidura en la que pudo colocarse un poste que sostendría una cubierta a partir de materiales perecederos. En Nakum, las banquetas en la fachada exterior podrían haber ejercido dicha función (figura 7).

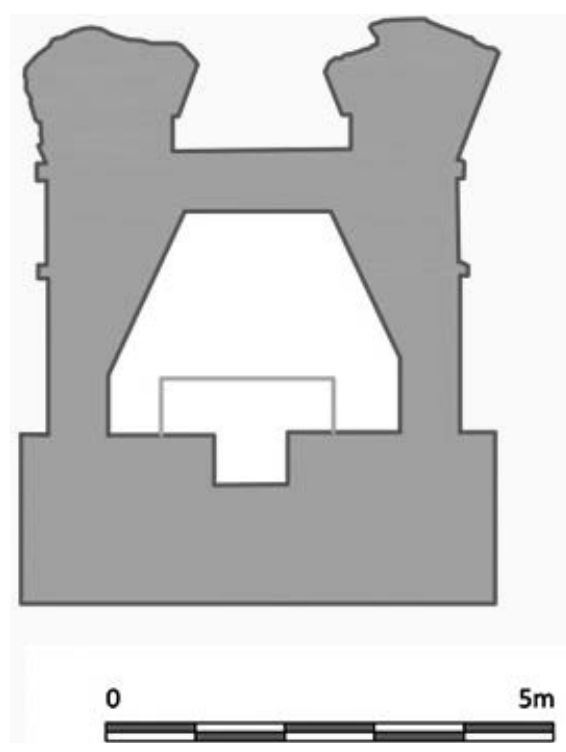

Figura 7. Sección de la cámara de vapor del edificio P7 de Piedras Negras a partir de los planos de Satterthwaite, 1952: fig. 47. Elaboración: Nuria Matarredona. 


\section{Conclusiones}

Está claro que sólo a partir del estudio exhaustivo del edificio puede diseñarse un modelo de conservación con ciertas garantías de éxito, y, precisamente por ello, resulta esencial comprender su arquitectura en sus dimensiones constructiva, funcional, estética e incluso simbólica. En la ciudad maya, en especial, este último punto cobra singular interés, puesto que cada construcción erigida persigue un fin comunicativo, la transmisión de un mensaje. El urbanismo y la arquitectura maya son el reflejo de la cosmovisión de esta civilización, y, por tanto, se requiere un conocimiento previo de su cultura para poder comprender sus manifestaciones arquitectónicas. Los temascales son un claro ejemplo de cuánto el análisis arquitectónico necesita apoyarse en el estudio de su contexto cultural.

Desde que se produjeran los primeros intentos de conservación arquitectónica en los sitios mayas, la identificación y puesta en valor consecuente de los baños de vapor ha contado con el gran inconveniente de una falta de datos sobre su funcionamiento, representatividad e importancia dentro de la sociedad. En efecto, se trata de una de las tipologías más desconocidas, y también fascinantes, del mundo maya. Para comprender su arquitectura se necesita una mirada desde diversos ángulos. El estudio del temascal no puede abordarse sino es desde la interdisciplinariedad, puesto que tan necesarios son los estudios antropológicos y etnográficos como los arqueológicos.

El estudio del temascal contemporáneo, apoyado en datos antropológicos y etnográficos, ha permitido elaborar una clasificación de sus principales rasgos característicos, definiendo los elementos necesarios para que una determinada construcción pueda funcionar como tal. La extrapolación de esta clasificación al estudio del baño de vapor prehispánico requería de un estudio histórico que analizase su evolución formal, funcional y simbólica. Esta retrospectiva del baño de vapor nos condujo hasta la documentación contenida en los códices y las crónicas relatadas por los primeros españoles llegados al Nuevo Mundo, que confirmaron que el temascal se empleaba de manera habitual entre los indígenas, y que desde entonces ha permanecido prácticamente invariable, tanto en forma como en contenido, durante los últimos 500 años.

Por otro lado, las crónicas evidencian el rechazo de los conquistadores a esta tradición, a pesar de alabar sus bondades terapéuticas, promoviendo incluso sanciones contra aquellos que lo emplearan, ya que contradecía los valores de la moral cristiana. Es decir, la conquista provoca que los indígenas practiquen el baño de vapor alejados de la ciudad y de las autoridades, donde construyen temascales de carácter humilde. Éste es el modelo de baño de vapor que ha trascendido hasta hoy. No debe olvidarse que en este momento ya se había producido el tan debatido "colapso cultural" maya que implicó el abandono de las ciudades de las Tierras Bajas centrales, pero no el de sus tradiciones, lo que implicaría que con toda posibilidad los mayas continuaron usando el temascal, pero no construyéndolo en su versión monumental dedicada a la alta sociedad, de una jerarquía ya rota en este momento. 
La sistematización de la información mediante fichas permite el análisis comparativo de estos temascales atendiendo a la época, ubicación o estado actual. El análisis de tales datos parece confirmar una mayor presencia de temascales monumentales en Tierras Bajas, especialmente durante el Clásico, circunstancia que contrasta con la situación actual, en la que su uso está asociado a climas más fríos. Atendiendo a su localización en la ciudad, el presente trabajo no ha detectado una asociación sistemática de estas estructuras con los juegos de pelota, tal y como había propuesto Agrinier (1966: 30).

Respecto a la cámara de vapor, podemos afirmar que unas dimensiones entre $8 \mathrm{~m}^{2}$ y $16 \mathrm{~m}^{2}$ de área y una altura entre 2.5 y $3.5 \mathrm{~m}$ resultan adecuadas para generar una atmósfera cálida y húmeda en un tiempo relativamente breve. En 2007 el grupo de investigación de Piedras Negras reprodujo un baño de vapor en P7 con un resultado altamente satisfactorio. En el caso de estancias cuya bóveda ha colapsado, como es el caso de Tikal, sólo queda la vía de una posible reconstrucción ideal a partir de las piezas localizadas, puesto que de otro modo no podría determinarse ni la altura del vano ni la propia de la estancia, y, por tanto, este rasgo identificativo quedaría invalidado.

Un acceso de dimensiones limitadas provisto de sistemas de cierre tales como pasa-cordeles facilitaría la conservación del ambiente apropiado durante mayor tiempo, minimizándose el consumo de energía. Por ello, se consideran imprescindible que la estancia sea de dimensiones menores a las habituales para cumplir satisfactoriamente la función de baño de vapor, y la presencia de pasa-cordeles u otros elementos de cierre, un rasgo oportuno aunque no determinante.

La sobreelevación de parte del espacio interior mediante banquetas permite al bañista acercarse a la mayor concentración de vapor, además de separar el área de movimiento de la de reposo. El elevado porcentaje de superficie ocupada por banquetas - de hasta un $90 \%$ - es indicativo de su función como temascal. En los de tipo popular, estas banquetas pudieran haber sido elementos de mobiliario, y, por tanto, podría no quedar evidencia de las mismas. Es decir, en temascales urbanos/monumentales, la existencia de un alto porcentaje de banquetas es un rasgo característico, mientras que en el caso de aquellos populares, no podría ser exigido como condición necesaria.

Respecto al hornillo para la producción de fuego, o al menos para el depósito de piedras calientes, podemos establecer que es fundamental para que un edificio de carácter monumental pueda ser considerado como temascal. Las evidencias arqueológicas que indican exposición a elevadas temperaturas, como el ennegrecimiento o las cenizas, se han considerado como indicadores de su función como baños de vapor. Algunas veces apuntan a que el fuego podría haberse encendido al exterior y los guijarros depositados en su interior una vez calientes, pero esto implicaría la aparición de evidencias asociadas a fuego en una distancia no muy lejana al posible temascal.

La disposición de las banquetas en todos los temascales estudiados comparados genera un corredor desde el hornillo hasta el acceso que facilitaría la evacua- 
ción de líquido en caso necesario. La pertinencia de un drenaje ha sido debatida a lo largo del texto, puesto que la condensación del agua evaporada no tendría por qué hacerlo necesario. Sin embargo, teniendo en cuenta que en determinados poblados hoy se refrescan tras el baño con jarras de agua, se considera oportuno analizar este parámetro como factor indicativo de idoneidad, aunque no como condición imprescindible.

El caso de los respiraderos es particular puesto que tan sólo se han localizado ventiladores propiamente dichos en Chichén Itzá y, además, no es un rasgo habitual en el temascal contemporáneo. Es probable que la necesidad de los mismos tenga mucho que ver con la producción de fuego dentro de la sala de vapor, puesto que esto los haría adecuados como modo de evacuación de humo.

Con referencia a las dependencias anexas dedicadas al reposo tras el baño, o a la preparación del mismo, se observa que resultan oportunas para un ritual completo, pero no son condición sine qua non para que un edificio sea considerado temascal, pues el bañista podría reposar en el exterior sobre esteras, como se realiza en la actualidad. En casos como Tikal se observa una hendidura en la que debió existir un poste de madera, traza de una cubierta anexa de madera que sirvió a esta misma función.

Así pues, atendiendo al carácter y localización de la construcción objeto de estudio, podemos distinguir una serie de rasgos tipológicos que resultan indicativos de su función como temascal. En definitiva, una correcta identificación resulta clave para la conservación y puesta en valor del mismo. 


\section{BIBLIOGRAFÍA}

Agrinier, Pierre

1966 "La casa de baños de vapor de San Antonio", Boletín Instituto Nacional de Antropología e Historia, 25: 29-32. México: Instituto Nacional de Antropología e Historia.

Ajxup Itzep, Mardoqueo Joel

1979 "Origen y desarrollo histórico del Temascal en Guatemala”, Antropología e Historia de Guatemala: Anuario de la Dirección General de Antropología e Historia de Guatemala, 1 (II época): 40-50. Guatemala: Dirección General de Antropología e Historia de Guatemala.

Alcina Franch, José, Andrés Ciudad Ruiz y Josefa Iglesias Ponce de León

1980 "El 'temazcal' en Mesoamérica: evolución, forma y función”, Revista Española de Antropología Americana [Trabajos y conferencias], 10: 93-132. Madrid: Universidad Complutense de Madrid.

Andrews , E. Wyliss IV y E. Wyliss Andrews V

1980 Excavations at Dzibilchaltun, Yucatan, Mexico. Middle American Research Institute. New Orleans: Tulane University (Publication 48).

Arreola, José María

1920 "El temazcal o baño mexicano de vapor”, Ethnos, 1 (1): 28-33. México: Secretaría de Educación Pública.

Codex Magliabecchiano

1904 Facsímil digitalizado, ed. Duque de Loubat. <http:/www.famsi.org/research/ loubat/Magliabecchiano/page_77r.jpg>.

Códice Tudela

2002 Facsímil, 2 vols. Madrid: Agencia Española de Cooperación Internacional y Desarrollo.

Cresson, Frank M. Jr.

1938 "Maya and Mexican Sweat Houses”, American Anthropologist, 40: 88-104. Wisconsin: American Anthropologist Association.

Cheek, Charles D. y Mary L. Spink

1986 “Excavaciones en el grupo 3, estructura 223”, Excavaciones en el área urbana de Copán, I, pp. 29-154, William T. Sanders (ed.). Tegucigalpa: Instituto Hondureño de Antropología e Historia.

Child, Mark B.

2007 "Ritual Purification and the Ancient Maya Sweatbath at Palenque", Palenque: Recent Investigations at the Classic Maya Center, pp. 12: 233-264, Damien B. Marken (ed.). Lanham MD: Altamira Press. 
Child, Mark B. y Jessica C. Child

2000 "Los baños de vapor de Piedras Negras, Guatemala”, XIII Simposio de Investigaciones Arqueológicas en Guatemala, 1999, pp. 1067-1087. Guatemala: Museo Nacional de Arqueología y Etnología.

2001 "La historia del Baño de Vapor P-7 en Piedras Negras, Guatemala”, XIV Simposio de Investigaciones Arqueológicas en Guatemala, 2000, pp. 449-464. Guatemala: Museo Nacional de Arqueología y Etnología.

Durán, fray Diego

$1995 \quad$ Historia de las Indias de de Nueva España e islas de tierra firme, 2 vols. (1588). México: Cien de México.

Gendrop, Paul

1997 Diccionario de arquitectura mesoamericana. México: Trillas.

González Mariscal, Jesús María

2007 "Temazcal: instrumento de armonización. El ejemplo del grupo de temazcaleros de Celaya”, tesis de maestría en Estudios Antropológicos de México. Puebla: Universidad de las Américas.

Groark, Kevin P.

1997 "To Warm the Blood, to Warm the Flesh: The Role of the Steambath in Highland maya (Tzeltal-Tzotzil) Ethnomedicine”, Journal of Latin American Lore, 20 (1): 3-96. Los Angeles: University of California, Latin American Center.

Ichon, Alain

1973 La religión de los totonacas de la sierra. México: Instituto Nacional Indigenista.

1977 "A Late Postclassic Sweathouse in the Highlands of Guatemala", American Antiquity, 42 (2): 203-209. Salt Lake City: Society for American Archaeology.

Jones, Christopher

1996 "Excavations in the East Plaza of Tikal (I, II)", Tikal Report, 16. Philadelphia: University of Pennsylvania.

Kirchhoff, Paul

1983 Principios estructurales en el México antiguo. México: Secretaría de Educación Pública.

Lowe, Gareth W. y Pierre Agrinier

1960 Mound 1, Chiapa de Corzo. Chiapas, México. Provo: Brigham Young University (Papers of the New Archaeological Foundation, 8).

Mason, J. Alden

1935 Mexican and Mayan Sweat-Baths. Museum Bulletin, 6 (2): 65, 67-69. Philadelphia: University of Pennsylvania.

McKee, Brian R.

1997 "La estructura 9 de Joya de Cerén: un temazcal del periodo clásico”, X Sim- 
posio de Investigaciones Arqueológicas en Guatemala, 1996, pp. 243-255. Guatemala: Museo Nacional de Arqueología y Etnología.

Morley, Sylvanus G.

1936a Guía de las ruinas de Quiriguá. Washington D.C.: Carnegie Institution.

1936b Chichén Itzá. Washington D.C.: Carnegie Institution (Carnegie Institution of Washington Year Book, 35).

1938 The Inscriptions of Peten, I-V vols. Washington D.C: Carnegie Institution.

Proskouriakoff, Tatiana

1946 An Album of Maya Architecture. Washington D.C.: Carnegie Institution (Publication 558).

Ruppert, Karl

1935 The Caracol at Chichen Itza, Yucatan, Mexico. Washington D.C.: Carnegie Institution (Publication 454).

1952 Chichen Itza: Architectural Notes and Plans. Washington D.C.: Carnegie (Institution Publication 595).

Sahagún, fray Bernardino de

1996 Historia general de las cosas de la Nueva España: Códice Florentino. Manuscrito 218-219-220 de la Colección Palatina de la Biblioteca Medicea-Laurenziana. Facsímil, 3 vols. Textos en castellano y náhuatl. Giunto, Firenze.

Satterthwaite, Linton, Jr.

1936a "An Unusual Type of Building in the Maya Old Empire", Maya Research. Mexico and Central America, 3 (1): 62-73. New Orleans: Tulane University.

1936b "Notes of the Work of the Fourth and Fifth University Museum Expeditions to Piedras Negras, Peten, Guatemala”, Maya Research. Mexico and Central America, 3 (1): 74-91. New Orleans: Tulane University

1952 Piedras Negras Archaeology: Architecture (Part V: Sweathouses). Philadelphia: University Museum of Pennsylvania.

Sharer, Robert J. y Wendy Ashmore

1979 Quirigua Reports I. Philadelphia: University of Pennsylvania.

Sharer, Robert J., Edward M. Schortman y Patricia A. Urban

1983 Quirigua Reports II. Philadelphia: University of Pennsylvania.

Sheets, Payson D.

1992 The Ceren Site. A Prehistoric Village Buried by Volcanic Ash in Central America. Fort Worth, Texas: Harcourt Brace.

Smith, A. Ledyard

1950 Uaxactun, Guatemala: Excavations of 1931-1937. Washington, D.C.: Carnegie Institution of Washington (Publication 588).

Taladoire, Eric

1975 "Les bains de vapeur et les systèmes d'eau dans leur rapport avec les ter- 
raines de jeux de balle”, Actas del XLI Congreso Internacional de Americanistas I, pp. 262-269. México: Comisión de Publicaciones de las Actas y Memorias.

Tozzer, Alfred M.

1957 Chichen Itza and its Cenote of Sacrifice. A Comparative Study of Contemporaneous Maya and Toltec. Memoirs of the Peabody Museum of Archaeology and Ethnology. Harvard University (XI, XII). Cambridge: Peabody Museum.

Tyrakowsky Findeiss, Konrad

2007 "Temazcales o baños de vapor en la región de Puebla-Tlaxcala: Elementos para un inventario de la cultura material del espacio rural”, Revista Española de Antropología Americana, 37 (1): 67-90. Madrid: Universidad Complutense de Madrid.

Wauchope, Robert

1948 Excavations at Zacualpa, Guatemala. New Orleans: Middle American Research Institute, The Tulane University of Lousiana (Publication 14). 